(C) 2010 The Authors. Aquaculture Research $\odot 2010$ Blackwell

Publishing Ltd

The definitive version is available at http://onlinelibrary.wiley.com/

\title{
Side effects of sexual maturation on heritability estimates in rainbow trout (Oncorhynchus mykiss)
}

\author{
Mathilde Dupont-Nivet ${ }^{1,}{ }^{*}$, Bernard Chevassus ${ }^{1}$, Stephane Mauger ${ }^{1}$, Pierrick Haffray ${ }^{2}$, Marc \\ Vandeputte $e^{1,3}$
}

\footnotetext{
${ }^{1}$ INRA, UMR1313 Unité de Génétique Animale et Biologie Intégrative, F-78350 Jouy-en-Josas, France

${ }^{2}$ Sysaaf, Section aquacole, Station SCRIBE, Campus de Beaulieu, F-35042 Rennes, France

${ }^{3}$ Ifremer, Chemin de Maguelone, F-34250 Palavas-les-Flots, France

*: Corresponding author : M. Dupont-Nivet, Tel : 331346523 49, Fax : 331346523 90, email address : Mathilde.dupont-nivet@jouy.inra.fr
}

Keywords: Fish, genetic parameters, sex effect, growth 
In fish, sexual maturation is often considered as a problem since it perturbs growth and product quality. Therefore, it is common to select against early-maturing males in commercial breeding programs (Gjedrem, 2000). Genetic determinism of age at sexual maturation has been extensively studied in many species with even some QTLs found (for example: Gjerde, 1986; Hankin, Nicholas \& Downley., 1993; Longalong, Eknath \& Bentsen, 1999; Kause, Ritola, Paananen, Mantysaari \& Eskelinen,, 2003; Haidle, Janssen, Gharbi, Moghadam, Ferguson \& Danzmann, 2008). However, the effect of sexual maturation on heritability estimates for other traits is not documented.

In this paper we present data collected during the beginning of sexual maturation of a group of rainbow trout and show how it biases heritability estimations. The fish studied were issued from a full-factorial mating between two dams and 45 sires. Fish were all reared in the same tank since eyed-stage under natural photoperiod and pedigrees were redrawn using ten microsatellites. Fish were harvested in April at 17 months old. They were killed on ice and several growth and quality traits were measured. Body weight was one of them, and is the production trait studied in this paper. Sex of fish was recorded by visual inspection of the gonads. For females, none of the individuals showed signs of maturation. For males, observers tried to differentiate non maturing and maturing males but it turned to be difficult because we were at the very beginning of the maturation (this rainbow trout strain usually spawns in November-December). However, we recorded gonads weight so that we were able to calculate gonado-somatic index (GSI $=100^{\star}$ gonads weight/body weight), which was used to determine which males were maturing or not. We studied several GSI thresholds: $0.1,0.2,0.3,0.4$ and 0.5 . For each threshold, males with GSI over the threshold were declared maturing males. We studied sex effect and heritability estimates for each threshold. Heritability was estimated using VCE5 (Groeneveld, 1990) with a sire model and sex and dam as fixed effects. Dam was set as a fixed effect because there were only two dams in our mating design, and therefore between-dams variance is of no interest. Two dams were used instead of one in order to avoid confusion of dominance effects with additive genetic effects in the between-sires variance. Moreover, this design was demonstrated to be efficient for estimating heritabilities when the total number of offspring analyzed is fixed (Dupont-Nivet, Vandeputte \& Chevassus, 2002). First, we analyzed all the dataset with a sex effect comprising three levels (female, male, maturing male). Secondly, maturing males were removed from the dataset and sex effect had two levels (male, female).

Using 'Fap' software (Taggart, 2007), $87 \%$ of fish could be attributed to their parents. Offspring from 2 sires with less than 3 offspring were removed from the data set. 433 animals were finally analyzed. Sex ratio was well equilibrated with 217 females i.e. $50.1 \%$. In Table 1 , proportions of maturing and non-maturing males are presented depending on the GSI value chosen for the threshold. Sex effects on body weight are also reported. Maturing males were significantly larger than non maturing males. The number of maturing males visually identified at slaughter was similar to that obtained from setting a GSI threshold of 0.4. In Table 2, we present heritability estimates for body weight either when all animals were kept for analysis or when maturing males were excluded from the dataset. Heritability estimates were much larger when maturing males were removed, and the lower the threshold, the higher the heritability estimate. Moreover, it appears that even if maturing males were recorded, addition of a maturing male level in the model was not enough to correct estimates. Thus, sexual maturation had a large impact on additive genetic variability of weight which could not be accounted for as a fixed effect in classical quantitative genetics models. Larger datasets should be needed to precisely estimate the magnitude of the effect of sexual maturation. Probably, physiological changes due to maturation highly perturb growth so that growth before and growth during maturation are two different traits, with different genetic determinism. This could partly explain the range of estimates found in the same species for the same trait, for example 0.1-0.6 for growth in rainbow trout (Gjerde, 1986; Martyniuk, Perry, Moghadam, Ferguson \& Danzmann, 2003). For breeding values, the consequences may also be important, leading to less efficient selection. However, this should be investigated further. 
For other traits, for example fatmeter data (indirect measure of fat level) for which there is no significant sex effect $(P>0.2)$, no effect on heritability was observed: estimates $(0.72-0.82)$ were similar whether maturing males were included in the dataset or not.

In most species, it is easy to find mature males but it is not possible to record which males are maturing if gonads are not observed or/and weighed. For traits influenced by sex, special care should be taken in new species for which physiology and consequences are not as well known as in salmonids. Even in salmonids, the question is not simple as maturing males cannot be externally identified in the early stages of maturation we described here.

The best solution is of course to measure fish before the onset of maturation, but this is not always possible if commercial sizes are targeted. Many breeding programs eliminate earlymaturing fish (Longalong et al., 1999; Gjedrem, 2000). Another solution used in rainbow trout is to work with triploid fish but this does not solve the problem for large sizes since male maturation is generally not totally suppressed in triploid fish. It is also possible to work with all-female populations, in which male maturation is, of course, not a problem anymore (Chourrout \& Quillet, 1982; Galbreath, 1994).

\section{References}

Chourrout, D., Quillet, E. (1982) Induced gynogenesis in the rainbow trout: sex and survival of progenies of all-triploid populations. Theoretical and Applied Genetics 63, 201-205.

Dupont-Nivet, M., Vandeputte, M., Chevassus, B. (2002) Optimization of mating designs for inference on heritability in fish species. Aquaculture 204, 361-370.

Galbreath P.F. (1994) Freshwater performance of all-female diploid and triploid Atlantic salmon. Aquaculture 128, 41-49.

Gjedrem, T. (2000) Genetic improvement of cold-water fish species. Aquaculture Research 31, 25-33.

Gjerde, B. (1986) Growth and reproduction in fish and shellfish. Aquaculture 57, 37-55

Glover, K. A., Taggart, J. B., Skaala, O., Teale, A. J. (2001) Comparative performance of juvenile sea trout families in high and low feeding environments. Journal of Fish Biology 59, 105-115

Groeneveld, E., Kovac, M. (1990) A generalized computing procedure for setting up and solving mixed linear models. Journal of Dairy Science 73, 513-531.

Haidle, L., Janssen J.E., Gharbi K., Moghadam H.K., Ferguson M.M., Danzmann R.G. (2008) Determination of Quantitative Trait Loci (QTL) for Early Maturation in Rainbow Trout (Oncorhynchus mykiss). Marine Biotechnology 10, 579-592.

Hankin, D.G., Nicholas, J.W., Downey, T.W. (1993) Evidence for inheritance of age of maturity in Chinook salmon (Oncorhynchus tshawytscha). Canadian Journal of Fisheries and Aquatic Science 50, 347-358.

Kause A, Ritola O, Paananen T, Mantysaari E, Eskelinen U (2003) Selection against early maturity in large rainbow trout Oncorhynchus mykiss: the quantitative genetics of sexual dimorphism and genotype-by-environment interactions. Aquaculture 228, 53-68

Longalong, F.M., Eknath, A.E., Bentsen, H.B. (1999) Response to bi-directional selection for frequency of early maturing females in Nile tilapia (Oreochromis niloticus). Aquaculture 178, 13-25.

Martyniuk C, Perry GML, Moghadam HK, Ferguson MM, Danzmann RG (2003) The genetic architecture of correlation among growth-related traits and male age at maturation in rainbow trout. Journal of Fish Biology 63, 746-764

Taggart J. (2007) FAP: an exclusion-based parental assignment program with enhanced predictive functions. Molecular Ecology Notes 7, 412-415 
Tables

Table 1. Data description : fish number and sex effect on mean body weight.

\begin{tabular}{|c|c|c|c|c|c|c|c|}
\hline \multirow[b]{2}{*}{$\begin{array}{l}\text { GSI } \\
\text { threshold } \\
\text { for } \\
\text { maturing } \\
\text { males }\end{array}$} & \multicolumn{3}{|c|}{ Fish number } & \multicolumn{3}{|c|}{ Mean body weight (g) } & \multirow[b]{2}{*}{$\begin{array}{l}\text { Sex } \\
\text { effect }\end{array}$} \\
\hline & $\begin{array}{c}\text { non } \\
\text { maturing } \\
\text { male }\end{array}$ & $\begin{array}{l}\text { maturing } \\
\text { male }\end{array}$ & female* & $\begin{array}{c}\text { non } \\
\text { maturing } \\
\text { male }\end{array}$ & $\begin{array}{l}\text { maturing } \\
\text { male }\end{array}$ & Female* & \\
\hline GSI > 0.5 & 178 & 38 & 217 & $\begin{array}{c}439.47 \\
b\end{array}$ & $\begin{array}{c}537.8 \\
a\end{array}$ & $\begin{array}{c}449.5 \\
B\end{array}$ & $<0.0001$ \\
\hline GSI > 0.4 & 148 & 68 & 217 & $\begin{array}{c}430.82 \\
b\end{array}$ & $\begin{array}{c}513.26 \\
a\end{array}$ & $\begin{array}{c}449.5 \\
B\end{array}$ & $<0.0001$ \\
\hline GSI > 0.3 & 113 & 103 & 217 & $\begin{array}{c}430.9 \\
b\end{array}$ & $\begin{array}{c}485.2 \\
a\end{array}$ & $\begin{array}{c}449.5 \\
B\end{array}$ & 0.0015 \\
\hline GSI > 0.2 & 67 & 149 & 217 & $\begin{array}{c}412.7 \\
b\end{array}$ & $\begin{array}{c}476.6 \\
a\end{array}$ & $\begin{array}{c}449.5 \\
A\end{array}$ & 0.0017 \\
\hline GSI > 0.1 & 23 & 193 & 217 & $\begin{array}{c}349.74 \\
b\end{array}$ & $\begin{array}{c}469.5 \\
a\end{array}$ & $\begin{array}{c}449.5 \\
A\end{array}$ & $<0.0001$ \\
\hline $\begin{array}{l}\text { Observed } \\
\text { maturity } \\
\text { status }\end{array}$ & 146 & 70 & 217 & $\begin{array}{c}433.0 \\
b\end{array}$ & $\begin{array}{c}506.3 \\
a\end{array}$ & $\begin{array}{c}449.5 \\
B\end{array}$ & $<0.0001$ \\
\hline
\end{tabular}

GSI : gonado-somatic index

*None of the females were identified as maturing

Means with different letters are significantly different $(P<0.05)$

Table 2- Heritability ( \pm S.E.) estimates of body weight

\begin{tabular}{lcc}
\hline $\begin{array}{l}\text { GSI } \\
\text { threshold }\end{array}$ & $\mathrm{h}^{2}$ for all animals & $\begin{array}{c}\mathrm{h}^{2} \text { when maturing } \\
\text { males are excluded }\end{array}$ \\
\hline $\mathrm{GSI}>0.5$ & $0.14 \pm 0.08$ & $0.16 \pm 0.09$ \\
$\mathrm{GSI}>0.4$ & $0.18 \pm 0.09$ & $0.21 \pm 0.11$ \\
$\mathrm{GSI}>0.3$ & $0.16 \pm 0.09$ & $0.33 \pm 0.15$ \\
$\mathrm{GSI}>0.2$ & $0.14 \pm 0.08$ & $0.36 \pm 0.15$ \\
$\mathrm{GSI}>0.1$ & $0.18 \pm 0.09$ & $0.60 \pm 0.20$ \\
Females & - & $0.61 \pm 0.21$ \\
only & &
\end{tabular}

